\title{
La violencia en escenarios educativos: un acercamiento multidisciplinario para su comprensión
}

Jesús Morales

Docente e investigador de la Universidad de Los Andes, Mérida, Venezuela; lectoescrituraula@gmail.com

\begin{abstract}
Resumen
La violencia como un fenómeno social ha representado científica e históricamente uno de los temas más controversiales, dada su complejidad. Ahora bien, dentro de los modos de violencia tipificados se encuentra la violencia perpetrada en escenarios educativos, cuyas implicaciones sociales se han convertido durante los últimos años en un fenómeno alarmante por el hecho de asumirse la institución educativa como un escenario en el que se intentan modular conductas, enseñar comportamientos y transmitir a través de los procesos de socialización las normas y convenciones pautadas por la sociedad. Se realiza una revisión de apreciaciones científicas derivadas de la psicología de la agresión, de la sociología de la violencia, de la educación y de la antropología, para dar cuenta de las motivaciones, repercusiones y componentes de la violencia en contextos educativos. Como parte de los resultados, se pudo evidenciar que la misma obedece a un fenómeno multifactorial que no puede ser visto desde una única postura, sino que debe involucrar la dinámica familiar, el contexto, los procesos evolutivos y de socialización y las representaciones culturales y sociales que poseen de la violencia tanto el sujeto activo como el pasivo.
\end{abstract}

Palabras clave: violencia en escenarios educativos, cultura, procesos de socialización, fenómeno multifactorial, convivencia social.

\section{Abstract \\ Violence in educative scenes: a multi-disciplinary approach for a understanding}

Violence as a social phenomenon, scientific as well as historically, has represented one of the most controversial themes because their undeniable complexity. In attention to this, diverse disciplinary statements have been generated as an attempt to expose the social and cultural motivations which take part in the manifestation of violence. Having said that, within of the different manners of the classify violence the perpetrated violence is found in educative scenes so that its social implications have become an alarming phenomenon during last years. That is so because the institutional educative centers have been considered as a scene in which they try to teach and mold behaviors and the social acceptable norms through the process of socialization in order to search the equilibrium and a healthy coexistence. Therefore, this essay does a review of scientific contributions related to violence studied by the field of psychology, sociology, education and anthropology in an attempt to give an account of motivations, effects and components of the violence in educative scenes. As a part of the results, 
it has been found that this multifactorial phenomenon answers to a diverse factors such as family, context, evolutionary processes and socialization as well as the cultural and social representations the individuals actives or passives have about violence.

Key words: violence in educative scenes, culture, processes of socialization, multifactorial phenomenon, social coexistence.

\section{INTRODUCCIÓN}

Generar un acercamiento a la comprensión de la violencia como representación del resquebrajamiento de las normas y acuerdos sociales consiste, entre otras cosas, en hacer mención a los procesos de discriminación y de persecución contra la disidencia, la diferencia y la diversidad (Bourdieu, 2000). De allí que, implícitamente, se haya asociado a la violencia con lucha cotidiana y permanente entre grupos sociales que intentan, entre otros cometidos, imponer sus formar de ver el mundo, conquistar espacios y proteger sus privilegios como medios permitidos y hasta naturales que garanticen el mantenimiento de su estatus.

En este sentido, el problema de la violencia como un fenómeno social ha sido apreciado desde diversas posiciones científicas, desde las cuales se han intentado explicar sus implicaciones, funcionamiento y dinámica, entre las que destacan perspectivas mecanicistas y biológicas, además de posturas socioculturales centradas en defender el efecto, la injerencia y los aportes que el contexto le aporta al individuo al configurar conductas y comportamientos violentos capaces de reproducirse en procesos de dominación (García \& Martínez, 2002). A estas perspectivas se han sumado otras derivadas de la psicología que han apreciado a la violencia no solo como el resultado de desajustes dentro de la interacción social, sino como producto del aprendizaje social de prácticas que, desarrolladas en forma reiterada y permanente, llegan a ser asumidas por el individuo como legítimas y aceptadas dentro de las relaciones con sus semejantes.

Junto a estas visiones científicas han emergido posturas teóricas que respaldan que la violencia responde a un proceso social desarrollado en forma sistémica a partir de las experiencias que el sujeto vive y de las que se apropia e interioriza en su acercamiento a la socialización (Puglisi, 2012). De allí que, a la participación de la familia, la escuela y la sociedad, se les atribuya la configuración y enseñanza de patrones comportamentales positivos y negativos debido a que sobre estos recaen funciones importantes centradas en la transmisión de los formar y convenciones sociales responsables de favorecer nexos de convivencia que preparan al nuevo individuo para interactuar con sus pares y con el mundo (López, 2008).

En atención a ello, es importante aclarar que las posturas expuestas deben ser concebidas no necesariamente en sentido antagónico, sino por el contrario desde la complementariedad, pues de cada una se desprende una construcción teórica de la violencia que la hace polifónica al permitir comprender cómo la herencia, el innatismo, el ambiente, la socialización, la cultura y el carácter simbólico, considerado como el conjunto de aspectos comunes y conocidos por el sujeto violento y la víctima, sobre los cuales se estructuran relaciones arbitrarias y de dominación que influyen en el hombre, determinan que su comportamiento sea más o menos propenso a incurrir en respuestas, reproducir actos y expresar comportamientos agresivos y violentos (Bourdieu, 2000; Murueta \& Orozco, 2015; Sen, 2007).

En este sentido, es condición fundamental el abordar la violencia desde una visión multidisciplinaria. De esta manera, con el presente ensayo se realiza una revisión de apreciaciones científicas derivadas de la psicología de la agresión, de la sociología de la violencia, de la educación y de la antropología, en un 
intento por dar cuenta de las motivaciones, repercusiones y componentes de la violencia desarrollada en espacios educativos, hasta llegar a realizar una caracterización del sujeto emisor y del sujeto receptor de la violencia.

\section{UNA APROXIMACIÓN MULTIDISCIPLINARIA AL FENÓMENO DE LA VIOLENCIA ESCOLAR}

La violencia como un fenómeno sociohistórico, ha marcado el proceso evolutivo de las vínculos humanos (Fromm, 1992). De allí que sus efectos multifactoriales y sus repercusiones hayan sido consideradas como una manera particular de dinamizar las relaciones sociales (Ferrandiz \& Feixa, 2004) y en las que la participación de la agresión, la explotación del fuerte sobre el más débil y el uso excesivo de la fuerza y la coacción han sido condiciones responsables de las más atroces expresiones de la naturaleza humana.

Por ende, la complejidad de la violencia ha merecido diversos pronunciamientos científicos desde los que se ha intentado dar cuenta de su dinámica, manifestaciones y matices, con el objeto de mostrar sus profundas implicaciones no solo a nivel social como espacio general, sino en escenarios educativos como un contexto con características particulares sobre el que ha recaído el foco de diversas disciplinas desde las cuales ofrecer razones pertinentes e integrar explicaciones que involucren sus repercusiones sociales a la luz de las experiencias evolutivas y de socialización sobre las que se cimienta la preparación del sujeto para convivir en los diversos espacios sociales.

En sentido amplio, se puede decir que a este proceso de acomodo y adaptación en el que se aprenden las convenciones sociales, se le han agregado una serie de cambios fisiológicos, físicos, emocionales y sociales, responsables del proceso normal de transición en el que el sujeto se confronta a sí mismo en una búsqueda recurrente por definir su identidad factor al que se le une el empezar a familiarizarse con nuevos roles que vienen a configurar una serie de demandas entre las que destacan su responsabilidad en su proceder y actuar.

Lo anterior, desde la psicología evolutiva representa la fase en la que el sujeto experimenta conflictos, rebeldías permanentes y luchas como expresiones que responden al rompimiento de la dependencia y a la asunción de nuevas actuaciones dentro del escenario social, familiar y educativo, lo cual se puede interpretar como una búsqueda incesante en la que el individuo intenta definir quién es y cuál es el espacio que ocupa a nivel social. Parafraseando a Aberastury y Knobel (1971) no es más que la estructuración de su identidad en la que participan como aspectos mediadores las interacciones grupales; es frecuente la ausencia de pensamiento pacífico, así como la práctica de conductas primitivas y agresivas; la recurrente presencia de comportamientos prosociales y de altruismo; la separación sistemática de las normas establecidas a nivel familiar y social, así como permanentes cambios anímicos que lo hacen ser en ciertos momentos altivo, agresivo y dado a la confrontación.

En consecuencia, esta manera de buscar su identidad se ve pronunciada en espacios educativos donde el aprendizaje humano y social no deja de estar permeado por relaciones defensivas que fungen como herramientas de respuesta que entrañan respuestas recurrentes contra lo normativo, constituyendo a su vez parte de su propio proceso de transición, en el que el individuo es capaz de desarrollar habilidades al servicio de la convivencia pacífica, en el que además se ve confluido por una multiplicidad de pequeñas identidades que vienen a enriquecer, desde el punto de vista cultural, la estructuración de relaciones de tolerancia como vínculo necesario dentro del mundo social que le permiten la comprensión

y el entendimiento de lo diferente y de lo diverso, aspectos que a mitigan los efectos del etnocentrismo como aspecto responsable de la mayoría de los conflictos en la actualidad (Sen, 2007). 
Frente a esta exposición, han emergido posturas teóricas que asumen la convivencia cultural como el camino para el entendimiento humano. De allí que autores como Putnam (2000) hablen de la inminente necesidad de favorecer procesos de interacción en los que el hombre consiga identificarse con el otro, con sus valores y formas de ver el mundo, para desde allí propiciar relaciones de encuentro en las que halle cabida la divergencia y la tolerancia como facilitadores del desarrollo de vínculos pacíficos, de solidaridad y de empatía.

Todo esto visto desde el escenario educativo indica que, si bien este espacio se caracteriza por lo diverso, por la variedad de relaciones y de sujetos que interactúan allí, también es un contexto cargado de riqueza cultural y de desencuentros en el que convergen cosmovisiones diversas, condición que posibilita la aparición de encuentros agresivos y violentos, que demuestran los matices y múltiples maneras de la convivencia humana en este microespacio en el que las identidades pueden interactuar construyendo vínculos que llevan a algunos sujetos a defenderla y a otros a buscar reconocimiento aún a costa del uso de la coacción y de expresiones agresivas.

De esta manera, el efecto de la identidad en un momento clave como la escolarización incluye una serie de aspectos responsables de forjar y configurar determinantemente la forma como el sujeto se integra, comparte y participa dentro de los valores y formas de vida presentes. En primer lugar, es frecuente que el autoconcebirse diferente y hasta superior provoque expresiones de intolerancia que llevan al sujeto a generar persecuciones recurrentes contra los que hacen parte de su entorno; en segundo lugar y desde la visión de la víctima, puede ser común la actitud repulsiva contra el sujeto dominante que intenta atribuirle su identidad, propiciando las condiciones para una sumisión acrítica, conformista e inteligente como parte del instinto normal de supervivencia o, en su defecto, el desarrollar un comportamiento irreverente dado a la objeción y a la no aceptación (Sen, 2007).

Todo lo expuesto, en palabras de Fromm (1992), se ha debido en parte a relaciones deprimentes, dominantes y excesivamente controladas que experimentan las sociedades, pues el común denominador dentro de expresiones agresivas y mediadas por la violencia es que han tenido como agente motivador la tradición histórica de la opresión, cuyo fundamento no ha sido otro que el apego a principios heredados de la desigualdad (Arent, 2006), a partir de los cuales han emergido reproducciones justificadas desde esquemas totalitarios en los que la presencia de arbitrariedades entre grupos constituye el elemento que permea las relaciones sociales, determinadas por la percepción que se tiene del otro, la cual muchas veces representa una imagen aumentada (Bourdieu, 2000), que define el que unos sujetos perciban como amenaza al otro, y asuman entre otras posiciones la sumisión y la obediencia como garantía de supervivencia.

Por otra parte, perspectivas críticas de la educación han esgrimido que los escenarios escolares no solo representan un componente de la socialización y el espacio para el aprendizaje de una nueva cultura, sino además un lugar cargado de contradicciones, en el que se presenta una profundización significativa de las diferencias entre clases, favoreciendo la discriminación, la efervescencia de los juegos de poder y los conflictos por cuestiones de género como expresiones presentes de forma más pronunciada en la escuela, por representar el centro en el que confluyen tanto diversas maneras de ver el mundo como subculturas con deseos ideológicos impositivos, con pretensiones dominantes e intereses diversos (McLaren, 2005) que entrañan el uso de la arbitrariedad como mecanismo de dominación y de la imposición como variables omnipresentes en las relaciones sociales (Bourdieu, 2000).

En este sentido, y aunque parezca una contradicción, la presencia de este tipo de matices dentro de las relaciones humanas se logra apreciar con mayor profundidad en la institución educativa, pues a pesar de ser un espacio para el aprendizaje de las convenciones propias de la interacción social positiva y el conocimiento de lo normativo, también se constituye en un foco cargado de agresión, de competitividad y de imposición en el que los grupos van forjando y legitimando conductas que una vez internalizadas 
por su práctica recurrente tanto en su contexto como a nivel cultural, son repudiadas o asumidas como un componente normal de la convivencia social (Murueta \& Orozco, 2015).

Lo expuesto, desde el factor identidad, al que se le ha dedicado especial atención desde diversas corrientes de pensamiento sociológico y psicológico, permite precisar que ante el desconocimiento de sí mismo y de las diferencias como sujeto social, es frecuente la asunción de conductas determinantes dentro del normal desarrollo de las relaciones sociales (Butler, 2006). Por tanto, indica que la identidad como fundamento sobre el que recae la consolidación de la percepción del mundo y del otro, es la responsable y a la vez el referente desde el cual el individuo es capaz de establecer vínculos y conexiones de afiliación que den cabida a la cooperación, a la tolerancia y sobre a la empatía con el distinto o, por el contrario, repudiar al que asumen diferente.

Por su parte Briceño-León (2007), desde la sociología de la violencia, asume los conflictos y la agresión social como parte de los componentes que dinamizan el mundo, por lo que su afirmación es perfectamente aplicable al escenario escolar, al que desde esta perspectiva científica se asume como un espacio en el que el sujeto asume "modos de crecer, de ser respetado, así como los mecanismos para sobrevivir ante las amenazas de otros, constituyéndose en una palanca de ascenso social" (p.73). Lo citado, desde el punto de vista cultural, indica que la violencia representa una respuesta común o natural del sujeto agresor, quien hace uso de ella para tratar de forjar su identidad y de conquistar su reconocimiento como persona dentro de su espacio de convivencia.

A la par de las apreciaciones citadas, los postulados psicoanalíticos sobre la adolescencia han expuesto que durante la etapa es frecuente que el sujeto en un proceso adaptativo rehúse someterse a las normas y cánones socialmente establecidos, por lo que su tendencia puede convertirse en la expresión de comportamientos violentos y respuestas agresivas exacerbadas como resultado de la definición de su identidad, la cual suele estar caracterizada por el desencadenamiento maximizado de conflictos que se traducen en reacciones que la mayoría de las veces persigue el ejercer dominio e imposición sobre terceros (Aberastury \& Knobel, 1971).

En otro orden de ideas y como factor determinante en el presente siglo, la responsabilidad de los medios de comunicación en la construcción de identidad, por su capacidad extensiva y dotada de efectividad, se constituye en un espacio cargado de escenas y expresiones que se legitiman al rendirle culto implícito o explícito a la imagen de la violencia, normalizándola como parte la dinámica de convivencia humana, desde la que se asume como un proceso de reconocimiento cultural que justifica la discriminación, la dominación autoritaria, el uso de la amenaza y la manipulación, así como la arbitrariedad y el atropello, todas manifestaciones que denigran la dignidad humana al configurar conductas cada vez más insensibles que degradan en el individuo su capacidad de asombro ante la injusticia y el maltrato (Kaplan, 2006).

Lo expuesto puede interpretarse como el resultado de un amplio proceso de socialización atribuida a los medios de comunicación, cuyo rol social ha trascendido la simple información para constituirse en un espacio movido por la transmisión masiva (implícita y explicita) de patrones culturales y sistemas simbólicos de amplio alcance como lo son el lenguaje y la comunicación (Bourdieu, 2000), aspectos responsables de inducir, la mayoría de las veces como lo expone Gómez (2013), a "aplicar excesos y a exteriorizar de alguna forma la fuerza en acto sobre otro implicando la intersubjetividad y las relaciones sociales" (p.33).

Lo anterior, llevado a etapas escolares, indica que la violencia no es más que el resultado de las imposición de identidades particulares y belicosas (Sen, 2007) que propician en el sujeto agresor el uso del terror, de la ira y de la intolerancia como expresiones enfocadas hacia la búsqueda de reconocimiento, en el que la demostración de poder se convierte en un cometido contra todo aquello que le represente amenaza. 
Así, la violencia puede ser vista como el resultado de la competencia existente entre diversas identidades, desde las que se concibe al otro, al diferente, como sinónimo de peligro o, simplemente, como objeto sobre el cual descargar instintos innatos de violencia que buscan erradicar algún factor externo sobre el que se tiene una representación amenazante (Freud, 2004).

En este mismo orden de ideas, posiciones centradas en la cultura y sus efectos han propuesto que las manifestaciones violentas son el resultado de relaciones autoritarias (docente-estudiantes), pues el sentido impositivo y la fuerza dominante de unos sobre otros, han llevado al sujeto a aprender prácticas y acciones agresivas, la mayoría de las veces legitimadas por el sujeto que la promueve, entre cuyos cometidos se encuentran la jerarquización y organización grupal como expresiones humanas que vienen acompañadas de la manipulación psicológica o el uso de la fuerza, la persecución por cuestiones de género, raza, clase social y estatus socioeconómico (Giroux, 2003), cuyas repercusiones determinan la presencia de alteraciones en la personalidad.

Desde la pedagogía crítica los planteamientos de Illich (1985) son pertinentes para dejar por sentado que el resultado de sociedades sumidas en la desescolarización, no es otro que la generación de distorsiones en la construcción y el aprendizaje de comportamientos, motivados por actuaciones arbitrarias y excesos de autoridad como manifestaciones perpetradas desde los grupos dominantes (clase social o Estado) quienes hacen uso de la agresión como un medio de control. Frente a ello, expone el mismo autor, que la respuesta de los sometidos a dominación sistemática no es otra que la asunción de una actitud subversiva con tendencia anárquica, contrarespuesta que busca contener los efectos de la violencia infligida.

Lo planteado llevado al espacio educativo, indica que la violencia posee diversas aristas a través de las cuales apreciarla. En primer lugar, sujetos acosados, ridiculizados y expuestos a la burla colectiva por figuras de autoridad institucional (docente) configuran las condiciones para la presencia de ira y frustración, cuyo accionar no necesariamente posee un enfoque hacia quien la promueve, sino contra un tercero que entra en el círculo agresivo, y sobre el cual recae la condición de receptor del temor (Butler, 2006) y, en segundo lugar, sujetos que provenientes de núcleos familiares sin estructura o disfuncionales en los que la violencia de género y entre pares concurren, consiguiendo en el escenario educativo el espacio para reproducir conductas hostiles, desafiantes y perturbadoras que vienen a alterar la dinámica de convivencia, provocando que el sujeto vea en la violencia una respuesta y un proceso normal dentro de las relaciones sociales, debido a que su legitimidad viene dada por los primeros factores de socialización (Illich, 1985).

Aunado a lo anterior, otras perspectivas que han intentado explicar la convivencia escolar y la violencia, le han atribuido una significativa preponderancia a la influencia del contexto, por considerarlo el responsable de la configuración y el aprendizaje de conductas pro-sociales, de adaptación y de empatía (Noel, 2009).

Por su parte, la sociología ha planteado que ambientes hostiles y permeados por violencia física o simbólica, constituyen espacios que favorecen la intensidad en la agresión, la intolerancia, la ira y la insensibilidad, así como la propensión en la generación de conflictos y enfrentamientos con otros sujetos participes de su entorno (Bourdieu, 2000).

En atención a lo expuesto, la psicología de la delincuencia ha expuesto que la conducta es modelada en forma determinante por el contexto, pues el mismo según expone López (2008) favorece "el aprendizaje, el reforzamiento, la réplica y la reproducción de conductas violentas como resultado de procesos de socialización dados en el escenario familiar y educativo, que lo configuran en un sujeto violento con tendencia a la práctica de actividades delictivas" (p.269).

En apoyo a la posición expuesta, Redondo y Pueyo (2007) esgrimen desde la psicología de la delincuencia que la violencia está asociada a procesos derivados del aprendizaje social, entre los que se destacan 
la imitación, la adquisición, la ejecución y la reproducción o el mantenimiento. Todo lo expuesto indica que existen condiciones o características que hacen propenso al sujeto a practicar actos violentos y agresivos, entre los que destacan una elevada impulsividad, irritabilidad, tendencia al riesgo, escasa empatía, oscilación en sus estados anímicos, dificultad para socializar y una creciente proclividad a uso de la intimidación y de la agresión para demostrar su capacidad de dominación.

A partir de los postulados de López (2008), se puede inferir que la violencia obedece a un fenómeno multifactorial que prepara al sujeto para agredir en forma sistemática a su víctima. Entre estos factores condicionantes se mencionan los siguientes: familias desarticuladas física y emocionalmente; un contexto deprimente en términos socioeconómicos y, por ende, con necesidades básicas insatisfechas; rechazo e indiferencia de los progenitores; bajo o limitado nivel educativo; padres con conductas predelictivas o delictivas; ausencia de disciplina y, en caso extremo, una supervisión con tendencia férrea o maltratadora. Todos los excesos citados responden a componentes de la violencia que configuran la personalidad del sujeto, cargándolo de hostilidad, frustración y de una intensa proclividad antisocial.

Lo expuesto en palabras de Sanmartín (2007) funciona de la siguiente manera: el sujeto violento en forma selectiva identifica a su víctima y esta adopta una posición sumisa por considerarlo más fuerte y del que acepta pasivamente agresiones físicas entre las que priman los golpes, los maltratos y las palizas, así como el maltrato psicológico como la denigración, los insultos, las amenazas y el terror.

Cualquiera que sea la modalidad de agresión, sus implicaciones son el resultado del abuso y de una relación de imposición entre un sujeto más fuerte sobre otro débil, en el que la intimidación y el miedo infligido sobre la víctima imposibilitan la detección de sus efectos devastadores, a los que se le suma la dificultad para identificar rasgos definitorios que permiten dar con el agresor, quien haciendo uso de la sutileza asume roles que van entre el mostrarse como víctima y como victimario.

En consecuencia, discutir de violencia en escenarios escolares es hablar desde la antropología de un espacio mediado por la armonía, la agresión y el conflicto como factores que transversalizan los vínculos sociales desarrollados en esta institución y, en los que no dejan de estar presentes procesos de socialización y de adaptación como componentes sobre los cuales gira, por un lado, el desarrollo de una identidad positiva, por el otro y en caso extremo el aprendizaje de mecanismos de defensa, actuaciones disruptivas, conductas divergentes y particulares con tendencia a todo lo que se denomine orden o sistema de convivencia.

En suma, las relaciones violentas se encuentran estrechamente vinculadas con la construcción de una identidad fundada en la anarquía y la agresión como componentes propios del sujeto en el siglo XXI, momento en el que las influencias sociales, culturales y comunicacionales determinan la asunción de comportamientos con tendencias competitivas, de inseguridad y de represión, como respuestas que configuran el proceder violento, desadaptado y conflictivo, que derivan en relaciones sociales problemáticas y en interacciones grupales negativas (Reguillo, 2007).

En otras palabras, y siguiendo los postulados de Galeano (1988), las condiciones sociales que experimenta el mundo han generado profundas relaciones de desigualdad y, por ende, de exclusión social como condiciones que han llevado a los grupos juveniles a trasladar sus formas de vida, sus valores y prácticas nocivas y disfuncionales a espacios educativos a los que han trasladado sus conductas negativas hasta el punto de constituirse en reproductores de la confrontación y el terror, cuya responsabilidad se le atribuye al componente institucional por su escasa capacidad para renovarse y responder a las necesidades reales de la sociedad.

Lo anterior se le puede adjudicar entonces, a la escasa pertinencia del sistema educativo como espacio de transformación social (Mclaren, 2005) cuyo rol se ha sumido en la imposibilidad según expone Reguillo (2007) de "generar procesos efectivos de socialización para la vida; dónde los espacios inclusivos den lugar a la diversidad; donde los procesos articuladores que integran la esfera pública integren 
otras voces y reconozcan al diferente" (p.15). Ello se traduce en la imposibilidad del aparato educativo, de desarrollar habilidades para la convivencia y la tolerancia como necesarios para mitigar el enojo, la ira y la frustración como componentes de la agresión presentes en contextos desarticulados y con niveles comunicativos muy bajos.

Lo anterior, desde una perspectiva antropológica, implica que el sujeto violento asume en términos de normalidad el agredir o maltratar físicamente, pues desde las representaciones mentales generadas a partir de las experiencias dadas en su círculo de socialización, éste llega a concebir los actos disruptivos y a los comportamientos violentos como componentes necesarios que median los vínculos sociales (Castañeda \& Torres, 2015; Garriga \& Noel, 2010). Visto desde la convivencia escolar, funciona de la misma manera, pues el sujeto frente a un escenario en el que empieza a aflorar la competitividad como parte de la construcción y de la búsqueda de identidad, participa activamente de expresiones de violencia y de dominación en contra de sus pares en un afán por conseguir que se le reconozca como sujeto parte de la sociedad.

Por tanto, el ambiente escolar es propicio para iniciarse y participar en la generación de pugnas, como respuesta frecuente entre quienes desean imponerse, aquellos que se resisten y los que definitivamente se dejan intimidar por el temor y el potencial maltrato, sentimientos que una vez percibidos propician en la víctima una postura sumisa por considerarla una de las maneras para sobrevivir y manejarse dentro de círculos de poder. Parafraseando a Guzmán (1990) representa un indicador del rol que asume el sujeto pasivo, consistente en interiorizar como legítima a la violencia presente en su entorno, lo que desde su propia percepción inconsciente le inhabilita y frena para manifestar cualquier intento de resistencia o contrarespuesta por considerarla inútil o difícil de superar.

Frente a la posición anterior, la psicología de la violencia propone que sujetos provenientes de núcleos familiares sumidos en espacios de dominación matriarcal o patriarcal, imposibilitan el manejo de un diálogo equitativo en el que la pluralidad y el respeto hacia el otro configuran una personalidad positiva, debido a que aspectos como la estima y el autoconcepto se ven modificados negativamente hasta propiciar la adaptación a condiciones hostiles cuya capacidad destructiva es casi imperceptible o normal (Pinillos, s/f) y, a su vez, legitimada por la violencia continua bajo la que se han dado sus relaciones familiares, culturales y sociales (Zicavo, 2015).

Lo expuesto anteriormente no es más que el resultado de la espiral de la violencia (Butler, 2006) en el que la represión, el temor y el dolor conducen a la víctima a un estado de profunda vulnerabilidad emocional, situación que es aprovechada por el agresor escolar para desarticular su estima, despojarle de su identidad (Galeano, 1988) e infligirle mayores niveles de agresión que le imposibiliten el oponer resistencia (Reguillo, 2007), llevando al sujeto a convertirse en agente receptor pasivo de prácticas disfuncionales reproducidas luego en las relaciones con sus pares y en el contexto social del que es parte.

Por otro lado, la antropología social, refiriéndose al sujeto violento y su potencial agresivo, ha propuesto que sus comportamientos son replicados en el escenario social cuando el mismo ha profundizado una serie de antivalores como el terror, el maltrato y la intolerancia contra el diferente; todo ello no es más que el resultado de una cultura violenta que le lleva a operar con toda normalidad en el uso de la represión, sin ningún tipo de sensibilidad. Se habla de la violencia como un conjunto de prácticas, códigos, costumbres y formas que desde la apreciación del sujeto agresor son propias de su contexto y de sus espacios de socialización, por lo que responden a un componente de las relaciones interpersonales en el que la dominación y el control excesivo de unos sobre otros es aceptable, rutinario y, si se quiere, normal (Bourdieu, 2000; Ferrandiz \& Feixa, 2004).

Desde una perspectiva biológica y ambientalista Sanmartín (2012) deja entrever que la violencia no es más que el resultado de una conducta dotada de intencionalidad, que lleva al sujeto agresor a ejecutar acciones conscientes con el propósito de infligir un daño físico o psicológico sobre la víctima. Mediante 
estudios desarrollados sobre el escenario escolar se describe a un sujeto con la disposición para perpetrar acciones violentas, con tendencia a controlar a terceros, que ante la imposibilidad de defenderse se someten forzosamente asumiendo un rol sumiso que les vuelve propensos al maltrato y a las pretensiones sistemáticas y recurrentes de su victimario.

La reacción de la víctima que da lugar a la represión y al sometimiento es vista desde la antropología como un claro indicativo de la existencia de un orden jerárquico rígido, implacable y dictatorial (matriarcado o patriarcado) proveniente del escenario familiar, que lo inclina a la subordinación, a la amenaza y, en caso contrario, a la configuración de una personalidad saturada de ira, rabia e impotencia como sentimientos que son trasmutados en actos violentos reproducidos en espacios sociales y colectivos (Morris, s.f.) siendo uno de ellos el escenario escolar, contexto en el que el sujeto interactúa, ajusta y construye la manera como se debe comportar y en el que arbitrariamente es obligado no solo a aprender reglas y normas de convivencia, sino a practicarlas en detrimento de su propia percepción del mundo (Kaplan, 2006).

Para la pedagogía crítica, la vida en las instituciones educativas muestra un elevado nivel de complejidad, pues en ellas convergen relaciones sociales mediadas por la competitividad, el desafío, la sobrevivencia y la permanente lucha de poder entre los actores educativos, quienes tratan de establecer desde distintas posiciones su perspectiva de orden, de justicia y de igualdad, valiéndose muchas veces de medios no convencionales para resistir el clima de control férreo en el que las imposiciones y el maltrato se dejan ver como instrumentos profundamente despóticos y opresivos (Mclaren, 2003).

Frente a lo planteado, Giroux (2003) esgrime que las relaciones de desigualdad promovidas y desarrollas a nivel político han tenido una creciente repercusión, reflejo e impacto en la configuración de la personalidad del individuo, quien ante la incapacidad crítica para discernir las relaciones nocivas que deterioran el orden social, asume un carácter reproductivo que llevado al campo educativo produce comportamientos y prácticas raciales y de discriminación que motivan la violencia y la agresión entre pares, docentes y autoridades institucionales.

Lo expuesto, parafraseando a Reguillo (2007), no es más que el resultado de la distribución poco equitativa de las condiciones de igualdad, lo que ha derivado en la construcción de espacios sociales con profundas exclusiones y limitaciones socioeconómicas sobre las cuales se han cimentado relaciones conflictivas, procesos tardíos de escolarización y la conformación de una cultura de la desadaptación a las convenciones sociales, cuyas repercusiones han tenido incidencia directa en la definición de la identidad del sujeto.

A la par, Kaplan (2006) expone que la violencia en escenarios educativos debe ser vista como un fenómeno que involucra una gama de percepciones, es decir, la de los actores educativos, quienes según sus representaciones mentales caracterizan lo que es violento de lo que no lo es. En atención a ello, los autores conciben que la violencia en este espacio social movido por lo diverso, se debe a la limitada capacidad de institución para generar condiciones flexibles, de participación, democráticos y de socialización progresiva, que le cooperen al sujeto en su proceso de adaptación a las normas sociales de convivencia y a la construcción de identidad.

Asimismo, el efecto de las políticas institucionales a nivel educativo, en lugar de generar las oportunidades necesarias para transformar al sujeto potencialmente violento, le condiciona y a la vez le estimula para la práctica de conductas agresivas, intolerantes y disruptivas como resultado de una enseñanza impositiva, desafiante y castigadora que sentencia severamente los errores en lugar de realizar ajustes de comportamiento que propicien mejores formas de interacción social y educativa.

Revisando toda la caracterización que motiva la manifestación de expresiones violentas en escenarios educativos, es imposible omitir la emergencia social que exige una transformación coyuntural del espacio educativo, en el que la destructividad humana no halle cabida (Fromm, 1973) y en el que se 
minimicen los efectos de la desigualdad social, la superioridad, la subordinación sistemática y los derivados de la discriminación (Galeano, 1988) y, en lugar de ello, se promueva la convivencia, la socialización y la reflexión sobre posibles formas para resolver pacíficamente las diferencias y los conflictos culturales (Butler, 2006; Galdung, 2003).

\section{LA VIOLENCIA ESCOLAR VISTA DESDE EL SUJETO ACTIVO}

La socioantropología ha hecho atribuciones importantes a la familia por considerarla como el primer escenario de socialización del individuo, es decir, el espacio en el que se consigue desarrollar inicialmente a través de un proceso de imitación y luego de aprendizaje, el interiorizar una serie de prácticas, acuerdos y convenciones para vivir en sociedad atendiendo a valores y conductas prosociales. Sin embargo, ello no siempre sucede de esta manera, pues estudios recientes a nivel psicológico han arrojado que sujetos formados dentro de los mismos esquemas positivos de socialización no necesariamente responden en forma coherente a las demandas de comportamiento altruista y social.

De esta manera y enfocándonos en la conflictividad llevada a cabo en escenarios educativos, la antropología ha realizado una tipificación del sujeto violento, al que se le ha visto como el resultado de hogares escasamente funcionales, fragmentados y con presencia de agresividad entre los padres, entre hermanos y demás miembros de la familia (Noel, 2009), cuestión que desde la psicología de la violencia ha sido concebida un proceso de aprendizaje de conductas y comportamientos nocivos que luego son replicados en otros escenarios y que fungen como determinantes de la relación con sus pares (Murueta \& Orozco, 2015).

Algunos rasgos que definen al sujeto que practica la violencia en escenarios escolares son: el uso desproporcionado y muchas veces ilimitado de poder; capacidad para intimidar valiéndose de sus cualidades físicas o psicológicas (habilidad para manipular); tendencia a la persuasión como medio de cohesión grupal, lo que le permite estar rodeado de adeptos que legitiman o coparticipan en sus prácticas. Aunado a ello, se vale del uso de un lenguaje denigrante cargado de insultos, el cual es usado sistemáticamente como medio de agresión que le permite intimidar (Sanmartín, 2007).

Lo expuesto se ha concebido desde la psicología como parte de los componentes de la violencia, cuya dinámica sigue una tendencia cíclica que envuelve inconsciente y conscientemente a la víctima y al victimario. Así, el sujeto agresor comienza replicando aquello de lo que fue receptor, apelando muchas veces a conductas y comportamientos aprendidos en escenarios iniciales de socialización que reforzados por experiencias externas (ejemplo: los medios de comunicación, las redes, las noticias) se asumen como los responsables de elevar los niveles de violencia e intensificar la gravedad de las lesiones que inflige, generando en la víctima profundas sensaciones de frustración y de intolerancia, así como la aparición de reiterados deseos destructivos (Fromm, 1973).

En este mismo orden de ideas, Pinillos (s.f.) realiza una caracterización desde la psicología de la agresión, en la que deja entrever los rasgos más evidentes desde los cuales identificar a un sujeto violento, entre ellos menciona los siguientes:

- Un elevado nivel de insensibilidad contra su víctima;

- una falsa sensación de amenaza que lo lleva a reaccionar en forma desenfrenada (no en todos los casos, pero sí en la mayoría);

- $\quad$ un incremento progresivo en lo que a destructividad se refiere;

- y el uso sistemático de maltratos físicos y verbales contra sus víctimas. 
Por su parte, Puglisi (2012) expone que el modus operandi del sujeto agresor se caracteriza como un proceso que "implica el uso de la intimidación y la victimización entre iguales, mediante el manejo de insultos, rumores, vejaciones, aislamiento social como manifestaciones de violencia física y psicológica" (p.4). Para esta autora los componentes más frecuentes dentro de la violencia escolar están determinados por una constante agresión física, el uso de la degradación de la autoestima, la humillación recurrente y la práctica de comportamientos dominantes cuya perpetración se presenta en forma sistemática.

En torno a lo expuesto, la psicología de la agresión plantea que el sujeto violento no es más que el resultado de una imposición cultural de identidades que impiden el reconocimiento del otro, del diferente y al que no se concibe desde la diversidad, sino que se asume como un sujeto receptor de toda su insensibilidad y frustración (Sen, 2007), componentes que dan paso a la degradación del autoconcepto de la víctima y, a la vez se constituyen medios para establecer la dominación y la violencia en la mayor parte de las relaciones que el individuo establezca (Bourdieu, 2000; Kaplan, 2006).

Parafraseando a Bourdieu, la violencia genera en el individuo una sensación de poder que lo lleva a ejercer acciones físicas y simbólicas contra sus víctimas, las cuales consisten en infligir temor, apoyarse en la discriminación y quebrantar la autonomía del diferente hasta lograr la creación de condiciones sobre las cuales fundar la imposición, la obediencia nociva y la subordinación del otro.

Desde la antropología, lo expuesto no es más que la persistencia de dos aspectos inherentes a la naturaleza humana que según Morris (s.f.) son por un lado, la permanente tendencia del hombre a establecer jerarquías sociales a través de la dominación de los que asume poco aptos o más débiles y, por el otro, la generación de luchas cruentas, agresivas y violentas para mantener el control de su espacio social. Estas razones representan motivaciones propias de las comunidades primitivas que siguen estando presentes y replicándose en los diversos escenarios de la convivencia humana en la modernidad, cuya dinámica apunta a acomodos realizados por la sociedad para organizarse.

\section{LA VIOLENCIA ESCOLAR VISTA DESDE EL SUJETO PASIVO}

El carácter sistémico de la violencia entraña en sí mismo la percepción de sus efectos en unos más que en otros (Viscardi, s.f.). Sin embargo, posiciones derivadas de la psicología de la violencia dejan entrever las motivaciones y la proclividad del sujeto a la dominación violenta, estas son: interacciones familiares fundadas en la agresividad, maltrato y temor, asunción de una postura tolerante; ausencia de condiciones de respeto, empatía y comunicación como mecanismos para negociar y resolver en forma pacífica los conflictos.

Entre otros aspectos, también se le atribuye la presencia de esquemas autoritarios y totalitarios cargados de represión, maltrato físico, psicológico y verbal, expresiones que en su carácter repetitivo y sistémico llevan al sujeto a asumirlo con total normalidad y desde una postura acrítica (Noel, 2009).

Frente a estas condiciones, es frecuente que el sujeto pasivo en el escenario escolar sea propenso al acoso y a la violencia, debido a su débil autoestima y a la ausencia de una identidad definida (Aberastury \& Knobel, 1971) que lo hacen vulnerable al sometimiento pasivo como un estado cuyas transformaciones se van agudizando hasta originar agresiones y maltratos que llevan al sujeto a asumir profundos estados de depresión y aislamiento, que por ser inconscientes muchas veces son imperceptibles.

En atención a ello, Murueta y Orozco (2015) mencionan una serie de características que vivencia el sujeto pasivo dentro del círculo violento escolar: es frecuente que la situación de riesgo en la que se encuentra, le lleve a retraerse y volverse poco comunicativo; experimenta estados de estrés y ansiedad que le imposibilitan mantener su equilibrio emocional; incurre en actos violentos involuntarios como resultado del hostigamiento sistemático; se percibe como un sujeto inútil, con una autoestima nula y en la que se 
piensa profundamente inferior hasta el punto de no apreciar sus potencialidades. Como consecuencia de lo anterior, es recurrente la presencia de comportamientos iracundos, de autocastigo, de incesante venganza y de frustración, cuya tendencia habitual es el homicidio y el suicidio.

Desde la perspectiva de Puglisi (2012), la violencia es percibida por el sujeto pasivo como el resultado del escaso reconocimiento que le dan sus compañeros, característica fomentada por su limitada popularidad como condición que le imposibilita para establecer relaciones de apoyo debido a la inconsistencia de su autoconcepto. De allí que la víctima asuma el rechazo desde la percepción del merecimiento, lo que porta la asunción de una personalidad retraída, insegura, tímida y desprovista de habilidades sociales necesarias para enfrentar el hostigamiento y los ataques que lo vulneravilizan y le otorgan poder a su agresor.

Parafraseando los planteamientos sobre la violencia realizados por Sen (2007), la falta de una identidad definida es concebida como un factor de riesgo, cuyas implicaciones son las responsables de llevar al individuo a asumir un comportamiento sumiso e incapaz de enfrentar la exclusión y la discriminación, condiciones que facilitan el sometimiento a sujetos violentos que percibiendo su debilidad se imponen, sometiéndolo a crueles castigos y agresiones físicas y psicológicas, como resultado de experiencias sistemáticas desde escenarios de socialización como el hogar y la familia que lo predisponen (López, 2008).

\section{REFLEXIONES FINALES}

Las perspectivas abordadas indican como necesario observar la violencia en escenarios educativos como una expresión heterogénea, en la que participan múltiples representaciones de la convivencia y de la vida en sociedad. Por tanto, se hace necesario entender la dinámica de interacción en la que los participantes del acto educativo exteriorizan su cosmovisión del mundo y sus valores y creencias, como factores desde los cuales se asume al otro desde el reconocimiento positivo fundado en el respeto y la tolerancia o, desde una apreciación negativa que lo percibe como potencial amenaza, generando en el sujeto violento la asunción de conductas hostiles, agresivas y de intimidación como mecanismos para neutralizar y enfrentar lo que desde su representación mental es una expresión de ataque y destrucción (Fromm, 1973; Puglisi, 2012).

Como se logró apreciar, la violencia en escenarios educativos obedece a un fenómeno multifactorial que debe ser visto desde diversos enfoques y posturas teóricas. Lo anterior indica que la construcción de un acercamiento a la comprensión de la violencia, requiere de la integración de aspectos como las creencias, los patrones y las estructuras de pensamiento familiar, el estudio del contexto, los procesos evolutivos y de socialización, la posición socioeconómica, el aspecto normativo y las representaciones de autoridad, como variables que determinan la asunción de respuestas positivas o negativas, que dan cuenta de las carencias presentes a nivel psicológico, social y hasta cultural (Freud, 2004).

En síntesis, la violencia escolar demanda para su estudio profundo la disposición para integrar los efectos derivados del contexto en el que la víctima y el victimario interactúan y comparten vida (padres, familiares, entre otros) y cuyas repercusiones determinan la construcción de vínculos empáticos o, por el contrario, manifestaciones nocivas tales como la agresión verbal y física, las vejaciones y el uso del maltrato, expresiones que permean las relaciones sociales. 


\section{REFERENCIAS}

Aberastury, A. \& Knobel, M. (1971). La adolescencia normal. Un enfoque psicoanalítico. Buenos Aires: Paidós.

Arent, H. (2006). Sobre la violencia. Madrid: Alianza.

Bourdieu, P. (2000). La dominación masculina. Barcelona: Anagrama.

Briceño-León, R. (2007). Sociología de la violencia en América Latina. Quito: FLACSO

Butler, J. (2006). Vida precaria. El poder del duelo y la violencia. Barcelona: Paidós.

Castañeda, M., \& Torres, P. (2015). Concepciones sobre la violencia: una mirada antropológica. El cotidiano, 7-9.

Ferrandiz, M. \& Feixa, F. (2004). Una mirada antropológica sobre las violencias. Alteridades, XIV (27), $159-174$.

Fromm, E. (1973). Anatomía de la destructividad humana. México: Siglo XXI.

Fromm, E. (1992). EL corazón del hombre. México: Fondo de Cultura Económica.

Freud, S. (2004). El malestar en la cultura. Madrid: Alianza.

Galdung, J. (2003). Violencia cultural. País Vasco: Centro de Investigaciones por la Paz.

Galeano, E. (1988). La escuela del mundo al revés. Madrid: Siglo XXI.

García, A. \& Martínez, J. (2002). Los conflictos escolares: causas y efectos sobre los menores. Revista Española de Educación Comparada, 8, 175-204

Garriga, J. \& Noel, G. (2010). Notas para una definición antropológica de la violencia: Un debate en curso. PUBLICAR - Año VIII (No IX), pp. 97-121.

Gómez, C. (2013).Violencia simbólica e interculturalidad. En Rizo, M \& Romeu, V. (Coords.). Comunicación, cultura y violencia. Barcelona. pp. 33-43. Universidad Autónoma de Barcelona.

Guzmán, A. (1990). Sociología y violencia. Bogotá: Universidad del Valle.

Illich, I. (1985). La sociedad desescolarizada. México: Editorial Joaquín Moritz.

Kaplan, C. (dir.). (2006). Las violencias en plural. Sociologías de la violencia en plural. Madrid: Miño y Dávila.

López, M. (2008). Psicología de la delincuencia. Madrid: Universidad de Salamanca.

McLaren, P. (2005). La vida en las escuelas. Una introducción a la pedagogía crítica en los fundamentos de la educación. Buenos Aires: Siglo XXI.

Morris, D. (s.f.). El mono desnudo. Un estudio del animal humano. Disponible en http://www.scribd.com/ Insurgencia

Murueta, M. \& Orozco, M. (2015). Psicología de la violencia. Causas, prevención y afrontamiento. Tomo II, 2 ed. México: Editorial El Manual Moderno.

Noel, G. (2009). La conflictividad cotidiana en el escenario escolar: una perspectiva etnográfica. Buenos Aires: Universidad Nacional de General San Martín.

Pinillos, J. (s.f.). Psicología de la violencia. Madrid: Universidad Complutense de Madrid.

Puglisi, B. (2012). Las escuelas como escenarios en los que se producen y reproducen violencias contra niños, niñas y adolescentes. Caracas: Instituto Latinoamericano de Investigaciones en Ciencias Sociales.

Putman, R. (2000). Sólo en la bolera: colapso y resurgimiento de la comunidad norteamericana. New York: Simon y Schuster. 
Sanmartín, J. (2012). Claves para entender la violencia en el siglo XXI. Ludus Vitalis, vol. XX, (núm. 38), pp. $145-160$.

Sen, A. (2007). Identidad y violencia. Madrid: Katz Editores

Viscardi, N. (s.f.). Violencia en aulas: práctica educativa, conflicto escolar y exclusión social. Módulo 3-Violencias. Monte Video: Ministerio de Educación del Uruguay

Zicavo, N. (2015). Hogar, violento hogar. En Murueta, M. \& Orozco, M. (2015). Psicología de la violencia. Causas, prevención y afrontamiento. Tomo II, pp. 17-30. 2 ed. México: Editorial El Manual Moderno. 